\title{
Figure of Merit Analysis of a Hybrid Solar-Geothermal Power Plant
}

\author{
Cheng Zhou ${ }^{1}$, Elham Doroodchi ${ }^{2}$, Behdad Moghtaderi ${ }^{1}$ \\ ${ }^{1}$ Centre for Energy, Discipline of Chemical Engineering, School of Engineering, \\ Faculty of Engineering and Built Environment, The University of Newcastle, Callaghan, NSW, Australia \\ ${ }^{2}$ Centre for Advanced Particle Processing and Transport, Discipline of Chemical Engineering, School of Engineering, \\ Faculty of Engineering and Built Environment, The University of Newcastle, Callaghan, NSW, Australia \\ Email: Behdad.Moghtaderi@newcastle.edu.au
}

Received 2013

\begin{abstract}
Figure of merit analysis is a general methodology used to evaluate whether a hybrid power plant could produce more power than two stand-alone power plants. In this paper, the assessment methodology using figure of merit analysis was re-examined for a hybrid solar-geothermal power plant. A new definition of the figure of merit was introduced specifically for a solar boosted geothermal plant to include both the technical and economic factors. The new definition was then applied in a case study of a hypothetical demonstration hybrid solar-geothermal power plant in Australia. The power plant was considered to have a typical net power output of $2.2 \mathrm{MW}$ with a solar energy fraction of $27 \%$. The analysis was performed to compare the power output and capital cost of the hybrid plant with the state-of-the-art (SoA) and existing stand-alone solar and geothermal plants. Based on the new definition, the hybrid plant was found to generally outperform the two existing stand-alone plants. Moreover, at an ambient temperature of $5^{\circ} \mathrm{C}$, the hybrid plant was found to outperform the SoA stand-alone plants when the geothermal temperature was greater than $150^{\circ} \mathrm{C}$. For geothermal temperature of $180^{\circ} \mathrm{C}$ on the other hand, the hybrid plant outperformed the SoA stand-alone plants at ambient temperatures lower than $33^{\circ} \mathrm{C}$.
\end{abstract}

Keywords: Figure of Merit; Hybrid Renewable Energy System; Solar; Geothermal; Power Generation

\section{Introduction}

In general, a hybrid power generation system can generate more power than two stand-alone power plants mainly due to an increase in efficiency. Such a synergistic effect alone, in most cases, makes the hybrid system more attractive than the stand-alone systems, not to mention other benefits that may be achieved simultaneously, for example, providing reliability to certain power generation systems (e.g. solar thermal power plant), prolonging plant service lifetime, and saving capital cost as well as operating and maintenance costs.

However, not all hybrid systems are inherited with a synergy, rather an improperly hybridised power generation system may even promote inefficiency. Thus, a methodology should be established to assess the availability and strength of the synergy. The figure of merit analysis developed by Khalifa et al. (1978) for a hybrid geothermal-fossil fuel plant is commonly used for such assessments [1]. However, Khalifa and his co-workers only provided the figure of merit analysis on a technical basis and therefore in their definition of figure of merits the economic factors were not considered. In the analysis of hybrid solar-geothermal systems, however, the economic factors cannot be ignored simply because sharing of power generation facilities in these plants is expected to greatly reduce their capital and operating costs relative to those of two stand-alone plants. Here we introduced a new definition of the figure of merit taking into account of both technical and economic synergies particularly in the context of a hybrid solar-geothermal system. Specifically a case study of the hybrid system was carried out to validate the new methodology.

\section{Figure of Merit Definitions}

The figure of merit developed by Khalifa, F, is defined in Equation (1) as the ratio of the power output of a hybrid power plant, $W_{h}$, to the sum of power outputs of standalone power plants, $W_{i}$;

$$
F=\frac{W_{h}}{\sum_{i=1}^{n} W_{i}}
$$

where $W_{i}=E_{i} \eta_{u, i} . E_{i}$ is the exergy content of the energy resource, and $\eta_{u, i}$ is the utilisation efficiency of the energy resource in a stand-alone power plant, $i$ de- 
notes the energy resource, and $n$ denotes the total number of the stand-alone power plants. In the definition of Khalifa, the figure of merit of larger than 1 indicates that the hybrid system outperforms the stand-alone systems in terms of power generation; however, other factors, such as resources availability, reliability of the hybrid system, and its economics are not factored in this definition.

To develop a figure of merit which considers the economic factors for a solar boosted geothermal plant, the following parameters were considered. For a stand-alone solar power plant,the overnight cost is largely for the power cycle and the solar field. In contrast, in a hybrid solar-geothermal plant for power generation, the overnight cost mainly depends on the solar field with minor costs ass $^{\circ}$ Ciated with the modification necessary for sharing of the power cycle infrastructure. The ratio of the total cost of solar in hybrid to the total cost of stand-alone solar, $\varepsilon$, was fixed at $76 \%$ for all analyses. The corresponding $24 \%$ cost reduction is largely attributed to the shared cost of the main power cycle, cooling system, engineering and management in a hybrid plant [2]. Taking into account the above considerations we define an economic figure of merit, $F_{\text {eco, }}$ which is the ratio of the cost per power output of the stand-alone solar

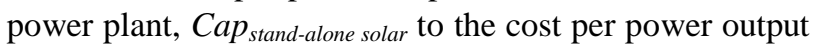
of the solar resource utilised in a hybrid plant, Cap solar in hybrid (Equation (2));

$$
F_{\text {eco }}=\frac{\text { Cap stand-alone solar }_{\text {Cap solar in hybrid }}}{\text { Can }}
$$

where

$$
\text { Cap stand-alone solar }=\frac{C_{\text {stand-alone solar }}}{W_{\text {stand-alone solar }}}
$$
and

$$
\text { Cap solarin hybrid }=\frac{\varepsilon C_{\text {stand-alone solar }}}{W_{\text {solar in hybrid }}}
$$

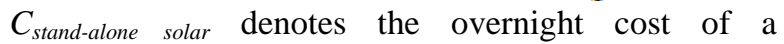
stand-alone solar power plant; $W_{\text {stand-alone solar }}$ denotes the power output of a stand-alone solar power plant; $W_{\text {solar in }}$ hybrid denotes the equivalent power output attributed to the solar resource in a hybrid plant (i.e. the boosted output); $\eta_{\text {stand-alone solar }}$ is the utilisation efficiency of solar resource in a stand-alone solar plant and $\eta_{\text {stand-alone geo }}$ is the utilisation efficiency of geothermal resource in a stand-alone geothermal power plant. Substituting the definitions of Cap $_{\text {stand-alone solar }}$ and Cap solar in hybrid in Equation (2) gives;

$$
F_{\text {eco }}=\frac{W_{h}-E_{\text {geo }} \eta_{\text {stand-alone geo }}}{\varepsilon E_{\text {solar }} \eta_{\text {stand-alone solar }}}
$$

In Equation (3), the economic figure of merit of larger than 1 indicates that the capital cost of utilising solar resource in a hybrid plant is lower than that of a standalone solar plant and hence, for the same power output, the hybrid plant is economically more feasible than the stand-alone power plants.

\section{Approach and Methodology}

Here both figure of merit definitions (i.e. Equations (1) and (3)) are applied to the following three scenarios as illustrated in Figure 1, in which the performance of a hybrid solar-geothermal plant is compared with two stand-alone reference power plants. These scenarios include, Scenario (a) where the two stand-alone reference power plants are considered to be SoA power plants with the maximum achievable utilisation efficiency, Scenario (b) where the two stand-alone plants are considered to be existing power plants each with their own Rankine power cycles (it should be noted that Rankine cycles generally have a lower utilisation efficiency than the SoA utilisation efficiency), and Scenario (c) where the two standalone plants are considered to be a combination of an existing geothermal power plant with a rankine power cycle and a SoA solar power plant with the maximum achievable utilisation efficiency. The latter Scenario specifically examines how well the solar resource is utilised in a hybrid plant compared to otherwise utilised in a SoA stand-alone solar power plant. The above scenarios are used to represent typical situations which can be encounetered in practice.

Corresponding to the three scenarios, figure of merits, $F_{a}, F_{\text {eco,a },} F_{b}, F_{e c o, b}, F_{c}$, and $F_{\text {eco,c }}$, were investigated, respectively. As can be seen in Equations (1) and (3), the calculation of figure of merit is a function of the utilisation efficiency of stand-alone reference power plants. This efficiency varies from a high utilisation efficiency of a SoA plant to a low utilisation efficiency of a nonSoA plant under the above senarios. Given that the hybrid power cycle in this case study was limited to an aircooled binary Organic Rankine Cycle (ORC), we assumed that the SoA utilisation efficiency of solar resource was $15 \%$ (a typical value in a SoA solar parabolic trough plant), and the SoA utilisation efficiency of geothermal resource was $30 \%$ (a typical value in a SoA geothermal

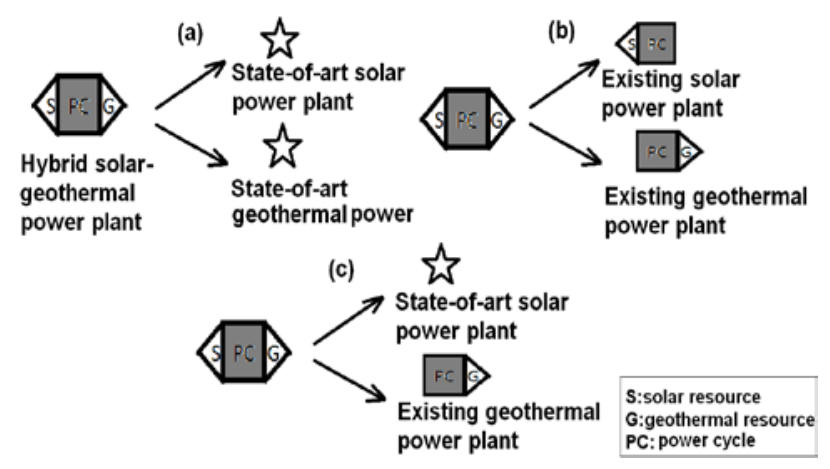

Figure 1. Three scenarios of figure of merit analysis, i.e. Scenario (a), Scenario (b), and Scenario (c). 
binary plant). It should be noted that in practice this efficiency varies widely ranging from $29.5 \%$ for a single-flash power plant to $35.6 \%$ for a dual-pressure binary power plant, $46.7 \%$ for a double-flash power plant, and $57.6 \%$ for a dry steam power plant [3].

\section{Hybrid Plant Model}

The hybrid solar-geothermal plant model, as shown in Figure 2, was established by using the $\operatorname{Pr}^{\circ}$ Cess simulation package, Aspen HYSYS. In this case study the power cycle of the hybrid system was selected to be an air-cooled binary ORC. The plant was composed of a basic air-cooled geothermal binary ORC and a solar heating system (i.e. the solar field) comprising a solar pump, solar collectors, and a superheater. The solar heating system was hybridised into the geothermal base power cycle to boost thermal efficiency and power. The geothermal base power plant used a demonstration power unit fed by a single well with a productivity of $50 \mathrm{~kg} / \mathrm{s}$ and a reservoir temperature of $150^{\circ} \mathrm{C}$, which was capable of producing a maximum available net power output of 1.5 MWe. The condensate entering the pump was always sub-cooled by $2^{\circ} \mathrm{C}$. For the solar field, a parabolic trough system with a heat transfer fluid of Therminol VP-1 was used. The solar field area was fixed to be $6000 \mathrm{~m}^{2}$, representing $27 \%$ solar energy fraction of the total heat input in the hybrid plant. The major parameters of the hybrid plant are summarised in Table $\mathbf{1}$.

\section{Results and Discussion}

The two definitions of the figure of merit were analysed under three predefined scenarios in the hybrid power plant. To conduct the figure of merit analysis, first the maximum available power output of the hybrid plant was calculated. Figure 3 shows the maximum available power output of the hybrid solar-geothermal plant with different solar field areas for geothermal reservoir temperaturs ranging between $90^{\circ} \mathrm{C}-180^{\circ} \mathrm{C}$. In this figure the power output results for a stand-alone geothermal plant (i.e. solar field area $=0 \mathrm{~m}^{2}$ ) at corresponding reservoir tem- peartures are also presented. Generally the solar heating system always boosted the power generation of the hybrid plant compared with a stand-alone geothermal plant, and the amount of boosted power was found to be directly proportional to the geothermal reservoir temperature and the solar field area. Moreover it can be seen that at a given power output, lower geothermal reservoir temperatures are needed as the solar field area increases. For example to generate 2.2 MW power output shown by the horizontal solid line, a lower reservoir temperature of $150^{\circ} \mathrm{C}$ is needed at $6000 \mathrm{~m}^{2}$ solar field area compared with $160^{\circ} \mathrm{C}$ for solar field area of $2000 \mathrm{~m}^{2}$.

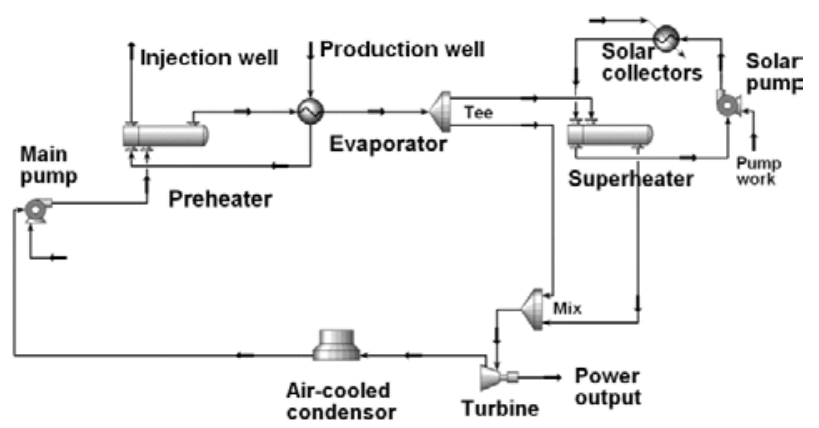

Figure 2. A diagram of a hypothetical hybrid solar-geothermal power plant.

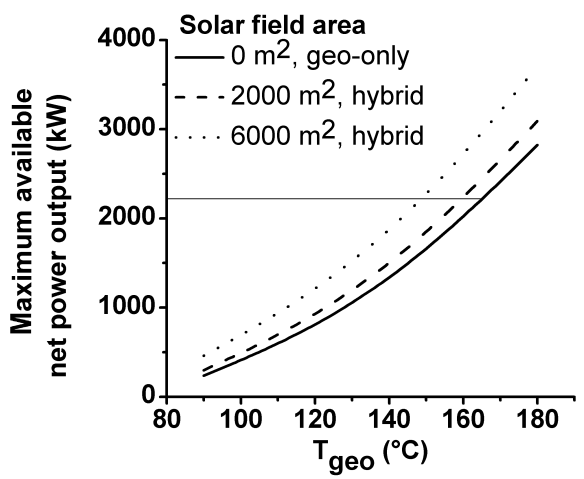

Figure 3. Maximum available net power output of the hybrid plant as a function of geothermal reservoir temperature, $T_{g e o}$ and solar field area.

Table 1. Simulation conditions used in the steady-state case study.

\begin{tabular}{|c|c|c|c|}
\hline Parameters & Value & Parameters & Value \\
\hline Production well temperature and flow rate & $150^{\circ} \mathrm{C}, 50 \mathrm{~kg} / \mathrm{s}$ & Design-point solar irradiance & $1000 \mathrm{~W} / \mathrm{m}^{2}$ \\
\hline Ambient temperature range & $5^{\circ} \mathrm{C}-44^{\circ} \mathrm{C}$ & Solar field area & $6000 \mathrm{~m}^{2}$ \\
\hline Organic working fluid & Isopentane & Optical efficiency of solar collectors & $70 \%$ \\
\hline Working fluid flow rate & $35.6 \mathrm{~kg} / \mathrm{s}$ & Solar working fluid high temperature & $390^{\circ} \mathrm{C}$ \\
\hline Isentropic efficiency of turbine & $80 \%$ & Minimum temperature approach of heat exchangers & $10^{\circ} \mathrm{C}$ \\
\hline Pump efficiency & $70 \%$ & Cost saving ratio of the hybrid plant, $\varepsilon$ & $76 \%$ \\
\hline SoA utilisation efficiency of geothermal resource & $30 \%$ & SoA utilisation efficiency of solar resource & $15 \%$ \\
\hline
\end{tabular}


While this figure provides information on how greater power outputs can be generated using a hybrid system, it does not provide any information regarding its competitiveness in terms of technical and economic benefits over two stand-alone geothermal and solar power plants. Such an evaluation was then carried out using the figure of merit analysis in Equations (1) and (3). The summary of the results for geothermal reservoir temperatures of $150^{\circ} \mathrm{C}$ and $180^{\circ} \mathrm{C}$ are preseneted in Table 2 and Table 3, respectively. At $150^{\circ} \mathrm{C}$ the original figure of merit showed that the hybrid plant produces $9 \%$ more power than the two existing stand-alone plants (i.e. $F_{b}=1.09$ ). However the hybrid plant failed to produce more power than two SoA stand-alone plants (i.e. $F_{a}=0.85$ ) as well as the combination of solar SoA and the existing geothermal plants (i.e. $F_{c}=0.90$ ). Similar trend was observed using the economic figure of merits where the hybrid plant under investigation was found to be inferior to a SoA stand-alone solar power plant or the combination of the solar SoA and the existing geothermal plants (i.e. $F_{\text {eco }}=$ 0.94 in Scenario (a) and Scenario (c)), indicating that the cost of the hybrid system was marginally greater than the stand-alone plants under investigations. The cost of solar in hybrid on the other hand was found to be approximately half of the cost of a existing stand- alone solar plant (i.e. $F_{\text {eco.a }}=1.91$ in Scenario (b)).

For the geothermal reservoir temperature of $180^{\circ} \mathrm{C}$, the calculated original figure of merits for Scenario (a) and (c) were 0.96 and 0.99 , respectively (Table 3) suggesting that the hybrid plant underperforms the two SoA standalone power plants (Scenario (a)) as well as the combination of the SoA solar and existing geothermal plants (Scenario (c)). However, the economic figure of merit for these scenarios $\left(F_{\text {eco,a }}\right.$ and $\left.F_{\text {eco,c }}\right)$ was calculated to be 1.27 indicating that from an economic perspective, the hybrid plant actually outperforms the two stand-alone power plants given in Scenario (a) and (c) overwriting the previous conclusion.

Also, the original and new figure of merit definitions for the hybrid plants given in Scenario (a), (b), and (c) were examined over a wide range of environmental conditions namely the heat source and heat sink temperatures. In this study, the geothermal reservoir temperature was varied from $90^{\circ} \mathrm{C}$ to $180^{\circ} \mathrm{C}$ and the ambient temperature was varied from $5^{\circ} \mathrm{C}$ to $44^{\circ} \mathrm{C}$. The comparative analysis results were shown in Figure 4 and Figure 5, respectively. In these figures the horizontal dashed line represents the conditions at which the hybrid and two stand-alone plants have the same performance.

Table 2. Simulation conditions and outputs for the case study with a geothermal reservoir temperature of $150^{\circ} \mathrm{C}$.

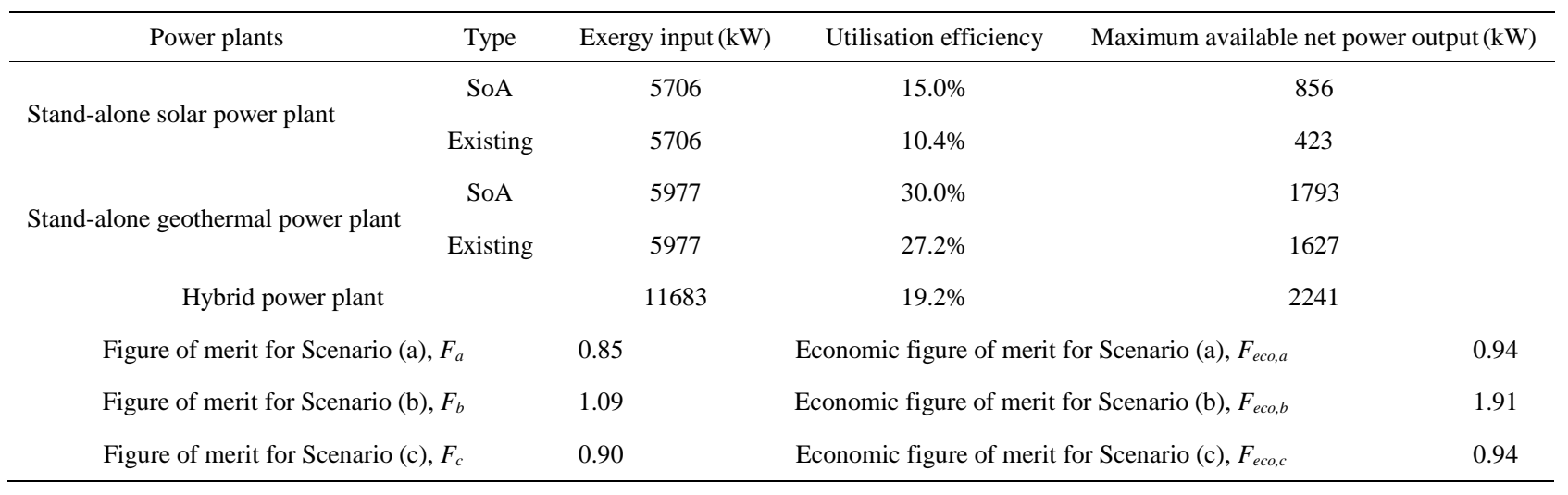

Table 3. Simulation conditions and outputs for the case study with a geothermal resource temperature of $180^{\circ} \mathrm{C}$.

\begin{tabular}{|c|c|c|c|c|c|}
\hline Power plants & Type & Exergy input (kW) & Utilisation efficiency & \multicolumn{2}{|c|}{ Maximum available net power output ( $\mathrm{kW}$ ) } \\
\hline \multirow{2}{*}{ Stand-alone solar pow } & SoA & 5706 & $15.0 \%$ & & \\
\hline & Existing & 5706 & $11.4 \%$ & & \\
\hline \multirow{2}{*}{ Stand-alone geothermal p } & SoA & 8360 & $30.0 \%$ & & \\
\hline & Existing & 8360 & $28.7 \%$ & & \\
\hline \multicolumn{2}{|c|}{ Hybrid power plant } & 14066 & $23.0 \%$ & & \\
\hline \multicolumn{2}{|c|}{ Figure of merit for Scenario (a), $F_{a}$} & 0.96 & Economic figure of mer & r Scenario (a), $F_{\text {eco,a }}$ & 1.27 \\
\hline \multicolumn{2}{|c|}{ Figure of merit for Scenario (b), $F_{b}$} & 1.06 & Economic figure of mer & r Scenario (b), $F_{e c o, b}$ & 1.67 \\
\hline \multicolumn{2}{|c|}{ Figure of merit for Scenario (c), $F_{c}$} & 0.99 & Economic figure of mer & r Scenario (c), $F_{e c o, c}$ & 1.27 \\
\hline
\end{tabular}



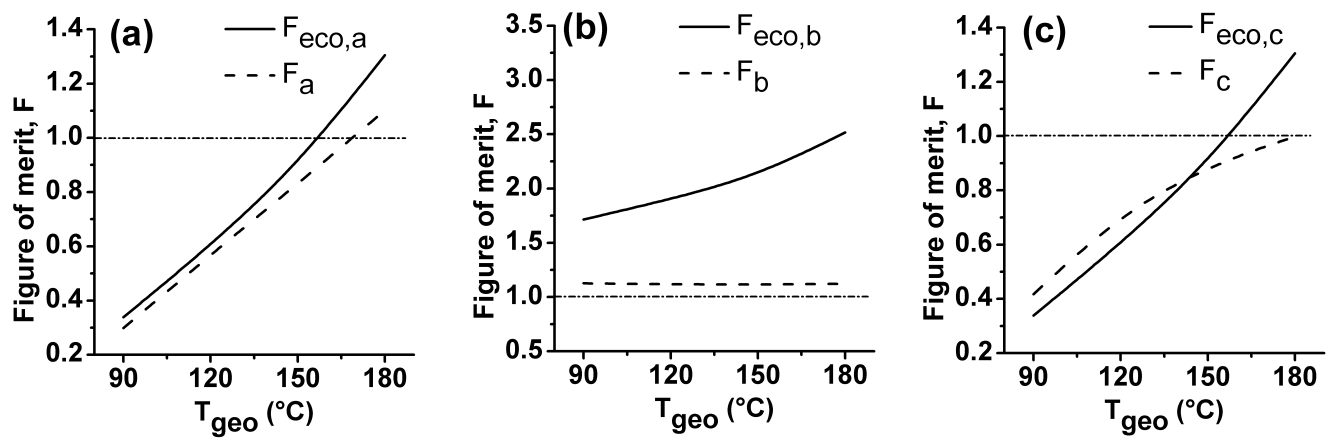

Figure 4. Comparison of figure of merits as a function of geothermal resource temperature at ambient temperature of $5^{\circ} \mathrm{C}$.
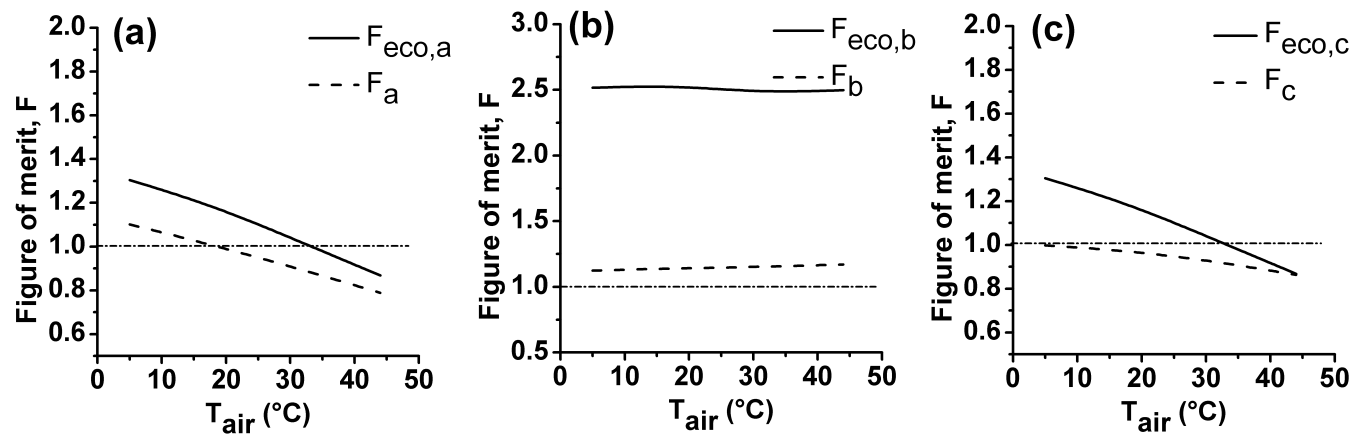

Figure 5. Comparison of various figure of merits as a function of ambient temperature at geothermal temperature of $180^{\circ} \mathrm{C}$.

Figure 4 shows that increasing the geothermal reservoir temperature in Scenario (a) and (c) increases the value of both figure of merits whilst the original figure of merit for Scenario (b) remains almost unchanged. These results show that in a case of using two SoA stand-alone power plants (Scenario (a)) or the combination of the SoA solar and existing geothermal plant (Scenario (c)), the hybrid plant became economically feasible at reservoir temperatures greater than $150^{\circ} \mathrm{C}$. However according to the original definition of figure of merit, the hybrid system requires a reservoir temperature of at least $170^{\circ} \mathrm{C}$ before it can outperform the stand-alone plants. The hybrid plant on the other hand was found to outperform, both in terms of power generation and cost, the existing stand-alone solar and geothermal plants.

As Figure 5 shows, an increase in ambient temperature reduces the values of both figure of merits in Scenario (a) and (c). However the ambient temperature was found to have a relatively negligible effect on the figure of merits for the Scenario (b). For the two SoA standalone power plants (Scenario (a)) or the combination of the SoA solar and existing geothermal plant (Scenario (c)), the hybrid plant became economically feasible at ambient temperatures less than $33^{\circ} \mathrm{C}$. Based on the original definition of figure of merit, however, the ambient temperature should be less than $20^{\circ} \mathrm{C}$ for the hybrid system to outperform the two SoA power plants in terms of power output. For the combination of the SoA solar and existing geothermal plant, the ambient temperature should reach sub zero temperatures before hybrid system became viable. Moreover, based on both definition of figure of merits, the hybrid system was found to outperform the two existing stand-alone power plants over the ambient temperature range examined in this study.

Clearly the new definition of figure of merit provides a greater insight into the assessment of hybrid Solar-geothermal power plants than the original definition of figure of merit simply by including the cost factor.

\section{Conclusions}

A new definition of figure of merit was developed considering both technical and economic parameters. The original and new figure of merit definitions were then applied to compare a hybrid solar-geothermal power plant with stand-alone plants using three scenarios. Based on the new definition, the hybrid system was found to generally outperform the two existing stand-alone plants. In a cold climate with an ambient temperature of $5^{\circ} \mathrm{C}$, however, the hybrid plant could only perform better than the two SoA stand-alone plants when the geothermal reservoir temperature was greater than $150^{\circ} \mathrm{C}$. As the geothermal reservoir temperature increased to $180^{\circ} \mathrm{C}$, the critical ambient temperature below which the hybrid system outperformed the SoA stand-alone plants raised to $33^{\circ} \mathrm{C}$. The cost of solar power generation per $\mathrm{MW}$ 
electricity in a hybrid power plant was predicted to be greater than the SoA stand-alone solar power plant, but $48 \%$ less than the existing stand-alone solar power plant. Overall, the results indicated that the new figure of merit provides a greater insight into the assessment of the hybrid system over the stand-alone power plants especially in a solar-geothermal context.

\section{Acknowledgements}

The authors thanks to the financial supports received from The University of Newcastle, Australia.

\section{REFERENCES}

[1] H. E. Khalifa, R. Dipippo and J. Kestin. "Geothermal preheating in fossil-fired steam power plants," $\mathrm{Pr}^{\circ}$ Ceedings of the 13 th Inters ${ }^{\circ}$ Ciety Energy Conversion Engineering Conference, Warrendale, PA, USA, 1978.

[2] Sargent \& Lundy LLC Consulting Group, “Assessment of parabolic trough and power tower solar technology cost and performance forecasts,” 2003. http://www.nrel.gov/d ${ }^{\circ} \mathrm{Cs} / \mathrm{fy} 040 \mathrm{osti} / 34440 . p d f$

[3] R. Dipippo, "Small Geothermal Power Plants: Design, Performance and Economics," Geo-Heat Center Quarterly Bulletin, Vol. 20, No. 2, June 1999. 